\title{
Application of digital colorimeter for preliminary characterization of gold nanoparticle swarms produced by Termitomyces heimii using a novel Bioinspired Microfluidics assay
}

\author{
Sujata Dabolkar and Nandkumar M. Kamat* \\ Mycological Laboratory, Department of Botany, Goa University, Taleigao Goa-403206, India \\ *Corresponding authorEmail: nandkamat@gmail.com \\ (Submitted on July16, 2020; Accepted on October 29, 2020)
}

\begin{abstract}
Fungi appear to be promising for large scale production of nanoparticles (NPs) as these are simpler to grow both in the laboratory and at industrial scale. This paper reports a novel microfluidics based assay system to detect Gold bioreduction capacity of different tissues in tissue based and cell free environment. Using sterile microtestplate, different tissues of Termitomyces heimii Natarajan mature fruitbodies were tested for bioreduction with $200 \mu \mathrm{L}$ chloroauric acid (one $\mathrm{mM}$ ) at an interval of 5,10, 15, 30, 45, 60, 120 min and 12, 24 and 48 hours. The results in terms of production of distinct nanoparticles were directly visualized microscopically and using mobile based digital colorimeter. Membrane filtered sterile water-soluble extracts (SWSE) from the same tissues were similarly screened. The results manifested by mono and polydisperse GNPs and microparticles of mixed size groups demonstrated that cell free system is potentially useful for bioinspired fabrication of GNPs.
\end{abstract}

Keywords: Microfluidistic assay, gold, bioreduction, termitophilic mushrooms

\section{INTRODUCTION}

During the present investigations Termitomyces heimii Natarajan being the most dominant species and a state mushroom of Goa, was used for microfluidic assay for rapid screening of gold bioreduction system, so as to detect and characterize swarms of gold nanoparticles formed by the collective behavior of GNPs. Mobile based digital colorimeter was used for the analysis so as to obtain spectra in the visible band. Such synthetic nanomaterials are of considerable interest as they are reported to have implications for the future in nanomachinery, nanomedicine, and chemical sensing (Kagan et al., 2011). The available digital tools are quite helpful in recording values such as CIE LAB, Chroma, $\mathrm{Hue}^{\mathrm{o}}, \mathrm{RGB}$, color names, real time visible spectra (400nm to $700 \mathrm{~nm}$ ), etc. The CIE LAB color space (also known as CIE $\mathrm{L}^{*} \mathrm{a}{ }^{*} \mathrm{~b}^{*}$ or sometimes abbreviated as simply "Lab" color space) refers to the color space defined by International Commission on Illumination (CIE) in 1976 which expresses color in three values where $\mathrm{L}^{*}$ stands for the lightness from black to white, $a^{*}$ from green to red, and $b^{*}$ from blue to yellow. Chroma (Saturation) refers to the strength or dominance of the hue, the quality of a color's purity, intensity or saturation (Solomon and Breckon, 2011). Hue is a common distinction between colors positioned around a color wheel. On the outer edge of the hue wheel are the intensely saturated hues whereas towards the center of the color wheel no hue dominates and becomes less and less saturated. The RGB color model is an additive color model in which red, green, and blue light are added in various ways to reproduce an array of colors (Meruga et al., 2014). Finally, it has been shown that absorbance peaks of GNPs are correlated to their size and the aim was to test the ability of digital colorimeter to get an idea of size distribution of GNPs in the swarms. Statistical analysis of the data was done using jvenn, a new JavaScript library (http://bioinfo.genotoul.fr/jvenn/ example.html), which processes lists and produces Venn diagrams with more than four lists, which are much harder to interpret. To solve this problem, the classical or EdwardsVenn representation introduced new shapes providing a clearer view (Philippe Bardou et al., 2014).

\section{METHODOLOGY}

Sample collection: Termitomyces heimii being the most dominant species and state mushroom of Goa was used for the present investigations. Fresh, healthy specimens of T.heimii (Natarajan, 1979) were collected from fields of Taleigao, Goa during monsoon season in 2019 and taxonomically identified using standard published Termitomyces literature (Natarajan, 1979) (Fig.1). Dried material of the mushroom was deposited in Goa University fungal herbarium under Herbarium number GUFH2177.

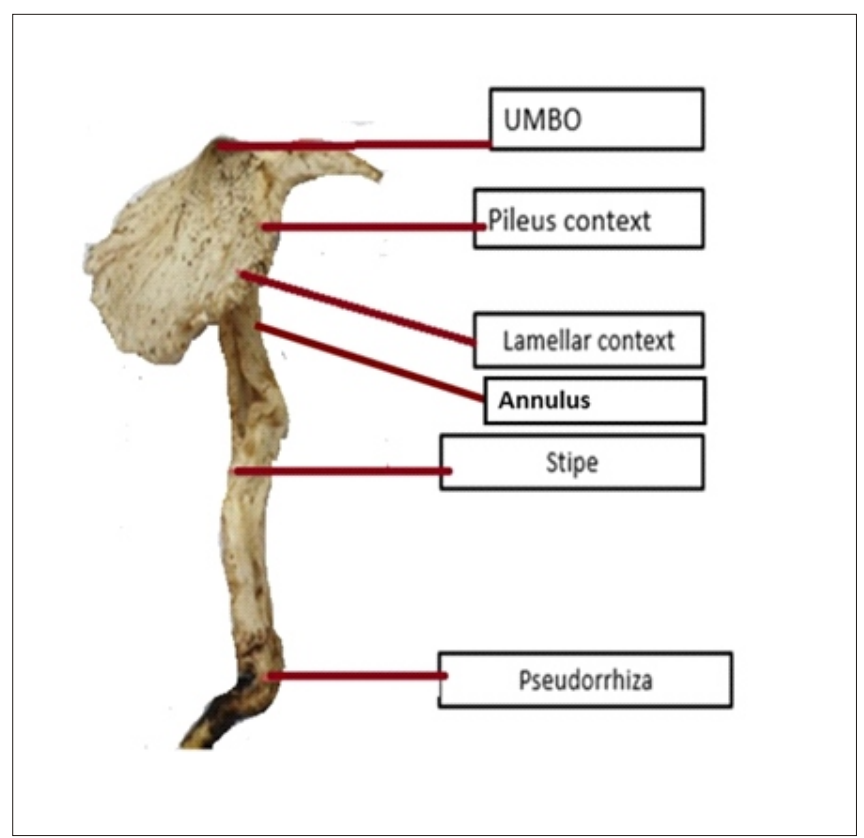

Fig.1. Scheme for specific processing of different fruitbody parts.

Processing of the specimens: The collected mushroom specimens were cleaned with $95 \%$ ethanol $(\mathrm{v} / \mathrm{v})$ for 30 seconds and subsequently photographed. Specific processing of each part of the fruitbody, i.e. umbonal tissue, pileus context, lamellae, stipe context, stipe epicutis, pseudorrhiza context, pseudorrhiza epicutis was carried out. Using a sterile forceps 
small pieces of the tissues were transferred into a microtest plate (Tarson, Mumbai) with 96 wells having volumetric capacity of $420 \mu \mathrm{L}$ under a Laminar air flow bench. Due care was taken to use identical appropriate fragments of tissue size equivalent to $200 \mu \mathrm{m}$. Tissues were tested with $200 \mu \mathrm{L}$ chloroauric acid (one mM) (Fig. 2) and at an interval of 5, 10, 15, 30, 45, 60, 120 minutes and 12, 24 and 48 hours. Nine replicates of each tissue were taken for experimentation.

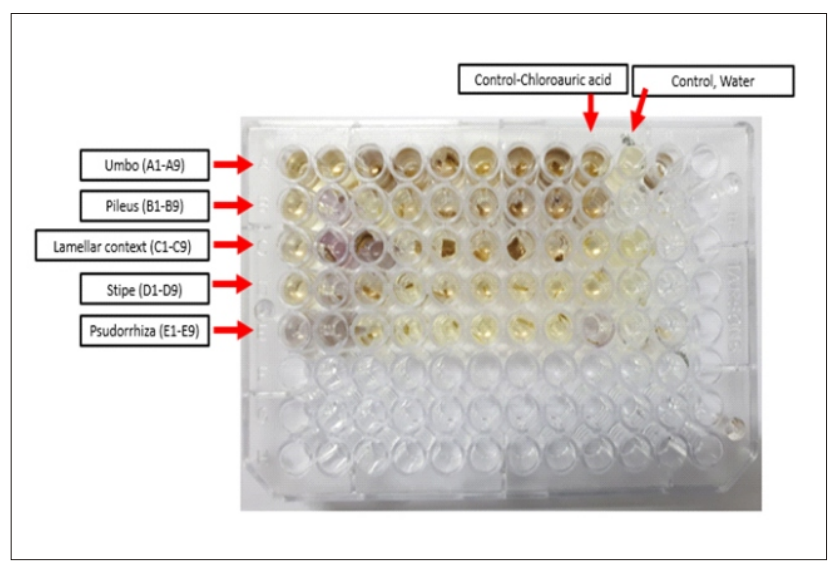

Fig.2. Design of Microfluidics based assay using Microtest plate.

Preparation of extracts: Sterile water-soluble extracts (SWSE) (Fig. 3) were prepared by grinding the material in sterile mortar and pestle, which was then centrifuged, and membrane filtered $(0.22 \mu \mathrm{m}$ pore size, $30 \mathrm{~mm}$ diameter, HIMedia laboratories). The SWSE were stored at refrigerated temperature in sterile test tubes. The extracts $(210 \mu \mathrm{L})$ and chloroauric acid $(210 \mu \mathrm{L})$ were mixed in an equal proportion in a well of microwell test plate and checked after interval of $5,10,15,25,30,45,60,120$ minutes and after 12, 24, 48 hours. The assay design has been depicted in fig.3.

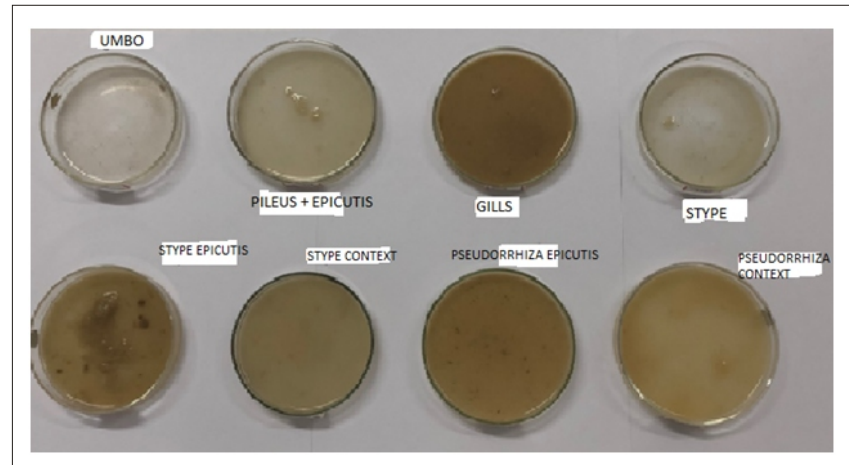

Fig.3. Homogenized aqueous extracts from different tissues.

Stereomicroscopic visualization of swarms: The microtest plate with the GNP swarms was visualized under stereomicroscope (Olympus SZ51, model SZ2-ILST, olympus corporation, Tokyo, Japan) (Fig.4). Due care was taken to bring the swarm view under uniform illumination in bright light.

Use of Digital Colorimeter: Scanning of the swarms was done using $12 \mathrm{MP}$ plus dual rear (F 1.5/ F 2.4) camera on Samsung Galaxy Note 9 with colorimeter software (http://researchlabtools.blogspot.com/) (Ravindranath et al., 2018) version 3.5.2, (developed by Research Lab Tools, São

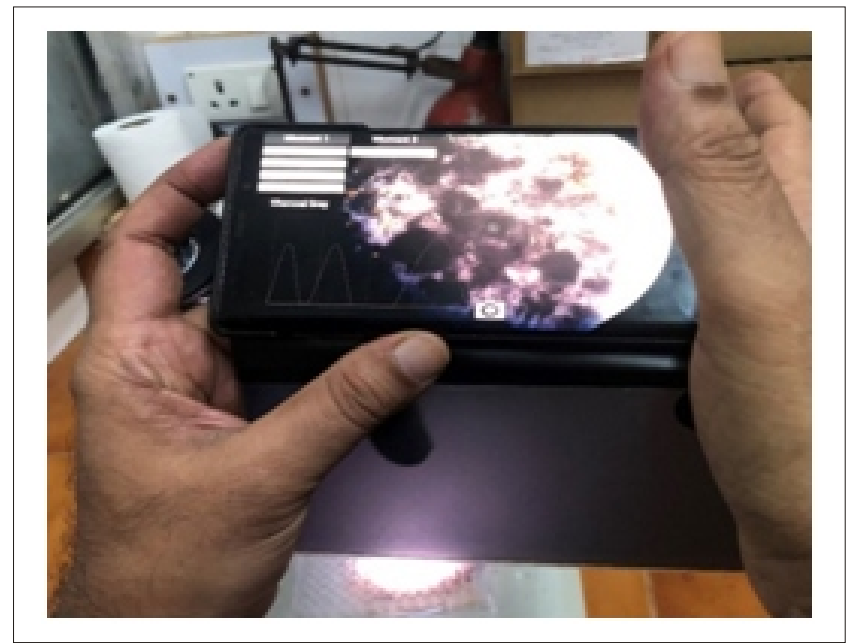

Fig.4: Direct Acquisition of images for stereomicroscopic characterization.

Paulo, Brazil; purchased from Google Play) which was installed on an android smartphone. There is a built in software for reading colorimetric absorbance between 350 to $700 \mathrm{~nm}$. Optical sensor is present in the smart phone. This is used for colorimetric operation by this software. Size was determined by standard relationship between the absorbance based on surface plasmon resonance and size of nanoparticles (https://www.sigmaaldrich.com, https://www/tedpella.com).

Digital color analysis and colorimetric data: The color terminology used is according to color data based on the App which allows online and offline analysis of samples. Colorimeter software was used to record values such as CIE LAB, Chroma, $\mathrm{Hue}^{\mathrm{o}}, \mathrm{RGB}$, color names, real time visible spectra ( $400 \mathrm{~nm}$ to 700 $\mathrm{nm})$. Among these Chroma and $\mathrm{Hue}^{\mathrm{o}}$ have no units of measurements (http://www.huevaluechroma.com)

Use of Venn diagram: Venn diagrams are commonly used to display list comparison. However, when the number of input lists exceeds four, the diagram becomes difficult to read. Alternative layouts and dynamic display features can improve its use and its readability. The jvenn library accepts three different input formats "Lists", "Intersection counts" and "Count lists". For "Intersection counts", the lists are given a label (" $A$ " or " $B$ ") which is used to make the correspondence between the list and its count. Finally, "Count lists" provide a count number for each element of a list. Hence, with "Count lists" the figures presented in the diagram correspond to the sums of counts of all elements shared between lists for "Lists" and "Count lists", jvenn computes the intersection counts and displays the chart (http://bioinformatics.psb.ugent.be/). Vein diagrams were plotted using tissues and lambda max values.

\section{RESULTS AND DISCUSSION}

Fresh and healthy specimens of Termitomyces heimii collected from the wild were taxonomically identified using standard published Termitomyces literature (Heim R. 1942, 1977; Natarajan, 1979; DeSouza and Kamat, 2018, 2019). GNP swarms detected within 12-24 hours and in all treatments were subsequently visualized under stereomicroscope (Fig. 5 \& 6). Umbonal tissue produced 


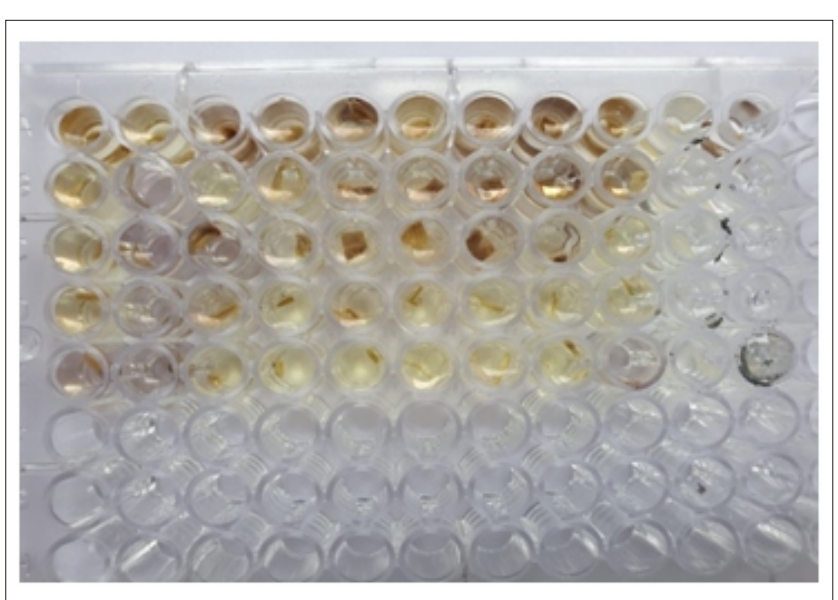

Fig. 5. Positive bioreduction obtained with homogenized tissues as indicated by color changes.

grey GNP swarms, the color values of which are shown in table 1. On overall basis the color ranges from grey to juniper green. The chromaticity values showed a difference and

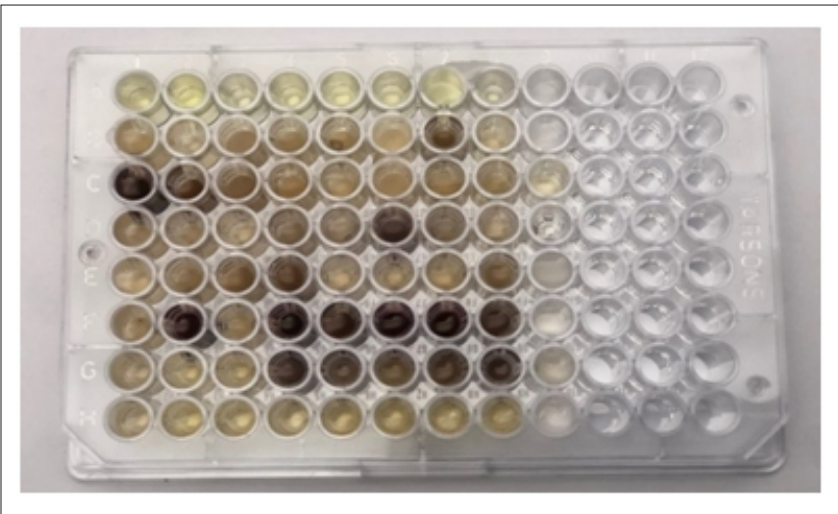

Fig. 6. Positive bioreduction with cell free membrane filtered SWSE indicated by change in colour, yellow is control.

chroma values ranging from 4 to 47 whereas Hue differed from 40 to 199 . The $\mathrm{R}$ value varied from 131 to $177, \mathrm{G}$ from 102 to 187 whereas B from 27 to 191 . Details of the

Table 1: Colour analysis and Colorimetric absorption characterization of presumptive GNP swarms.

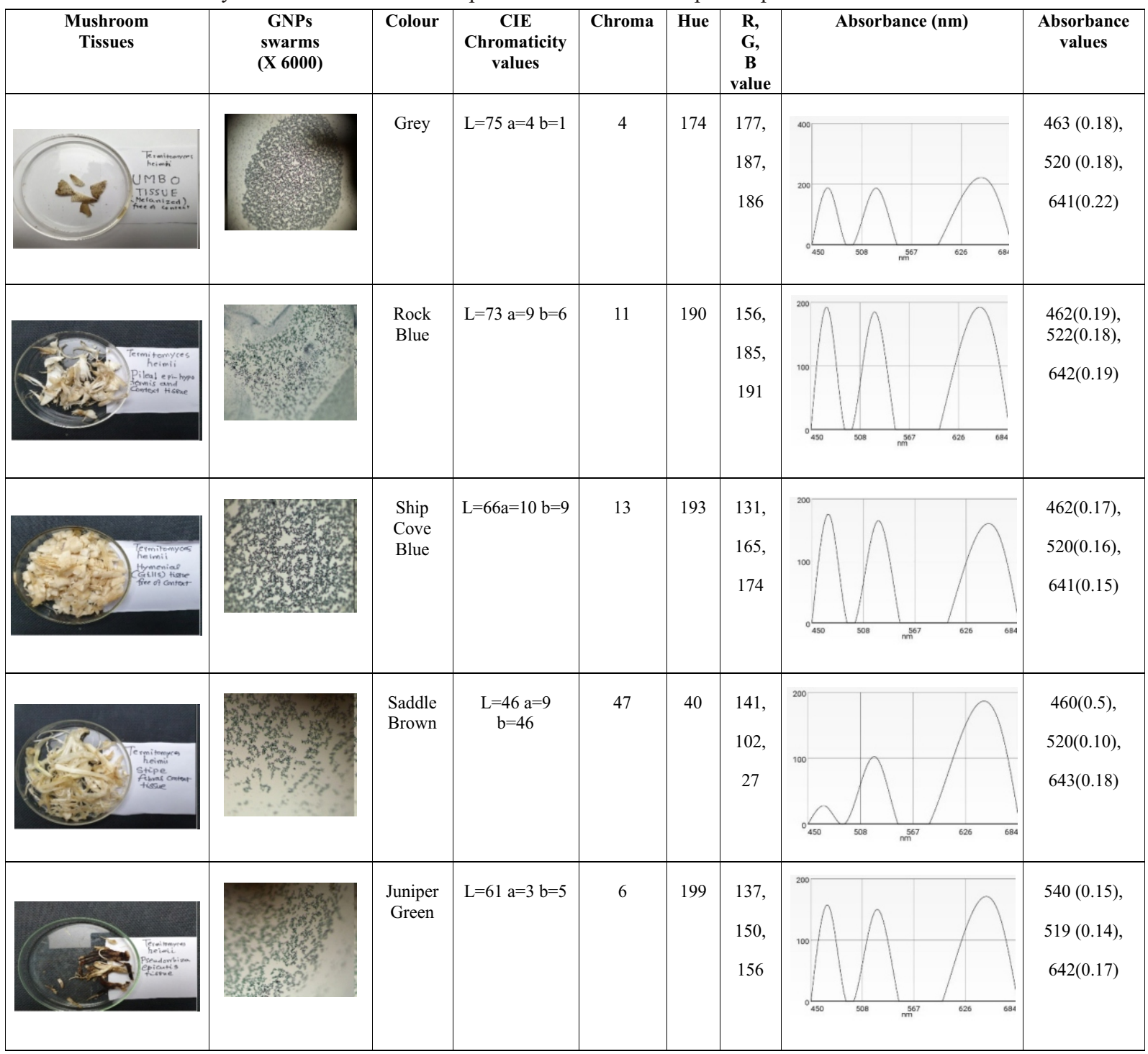


Table 2: Colour analysis and Colorimetric absorption characterization of presumptive GNP swarms

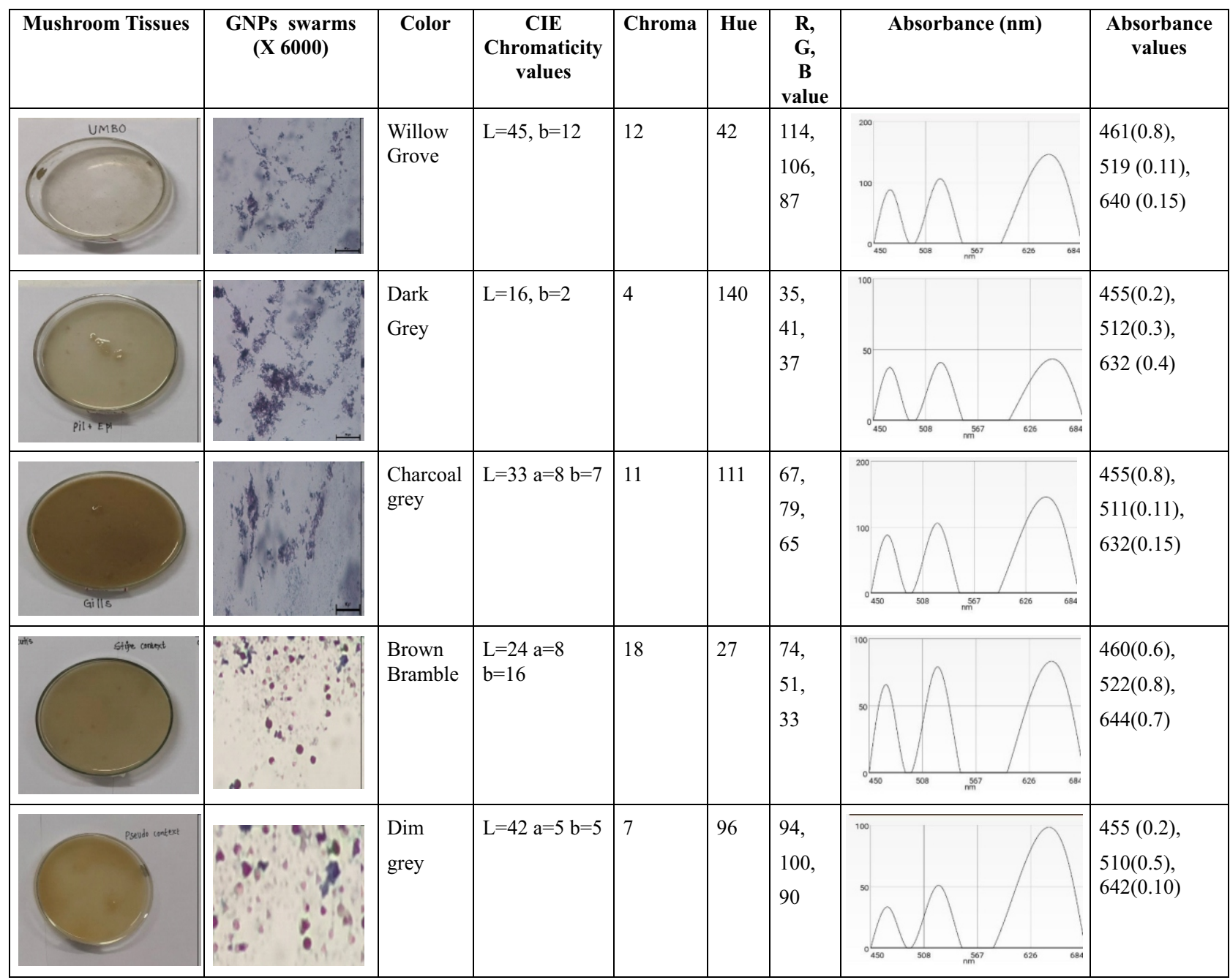

absorbance values obtained are given in table 3 . Similarly, the colors, color analysis and absorbance values of other tissues and SWSE are shown in table1 and table 2 . In table $\mathbf{3}$ values of thirty different peaks obtained using each tissue and extract are given. The absorbance value ranged from $455 \mathrm{~nm}$ to 644 $\mathrm{nm}$. Stipe exhibited most promising results with peaks at 455 , $510,642 \mathrm{~nm}$. Table 4 gives approximate GNP size range diameter which ranged from $5 \mathrm{~nm}$ to $100 \mathrm{~nm}$. It was noticed that only extract system was producing GNP swarms at wavelength of 455 , whereas only umbonal tissue produced maximum absorption at $461 \mathrm{~nm}$. Similar results were obtained in remaining reaction as shown in table 3 . Venn diagram analysis which are shown in fig. 7a-f.

In the novel microfluidics based assay system performed during the present investigations to detect Gold bioreduction capacity of different tissues from mature fruitbodies of Termitomyces heimii, viz. umbonal tissue, pileus context, lamellae, stipe context, stipe epicutis, pseudorrhiza context, pseudorrhiza epicutis (Kalia and Kaur, 2018; DeSouza and Kamat, 2017; 2018; 2019) in tissue based and cell free environment resulted in the production of GNPs for the first time. Success was also achieved in producing membrane filtered SWSE from the same tissues and GNPs from the same extracts. This assay is quite useful in working out large number of replicates under sterile forms. Microtest plates can be directly visualized due to their transparency and swarms can be directly characterized under stereomicroscope. Small amounts of gold solutions and SWSE can be tested using this microfluidic assay. This assay is also useful in rapid screening of large number of biological or microbiological gold bioreduction systems.

In case of tissues, the colour varied from grey, rock blue, ship cove blue, juniper green to saddle brown where as in case of SWSE it was willow grove, drim grey, dark grey, charcoal grey to brown gramble. For small $(\sim 30 \mathrm{~nm})$ monodisperse gold nanoparticles, the surface plasmon resonance phenomenon resulted in the absorption of light in the bluegreen portion of the spectrum $(\sim 450 \mathrm{~nm})$ while red light $(\sim 700$ $\mathrm{nm}$ ) was reflected, yielding a rich red color. As particle size increases, the wavelength of surface plasmon resonance related absorption shifted to longer, redder wavelengths (https:/www.sigmaaldrich.com/). Larger the size, darker is the color and which may also shift to blue in case of colloidal particles (Jana et al., 2001; Haiss et al., 2007; Martinez et al., 

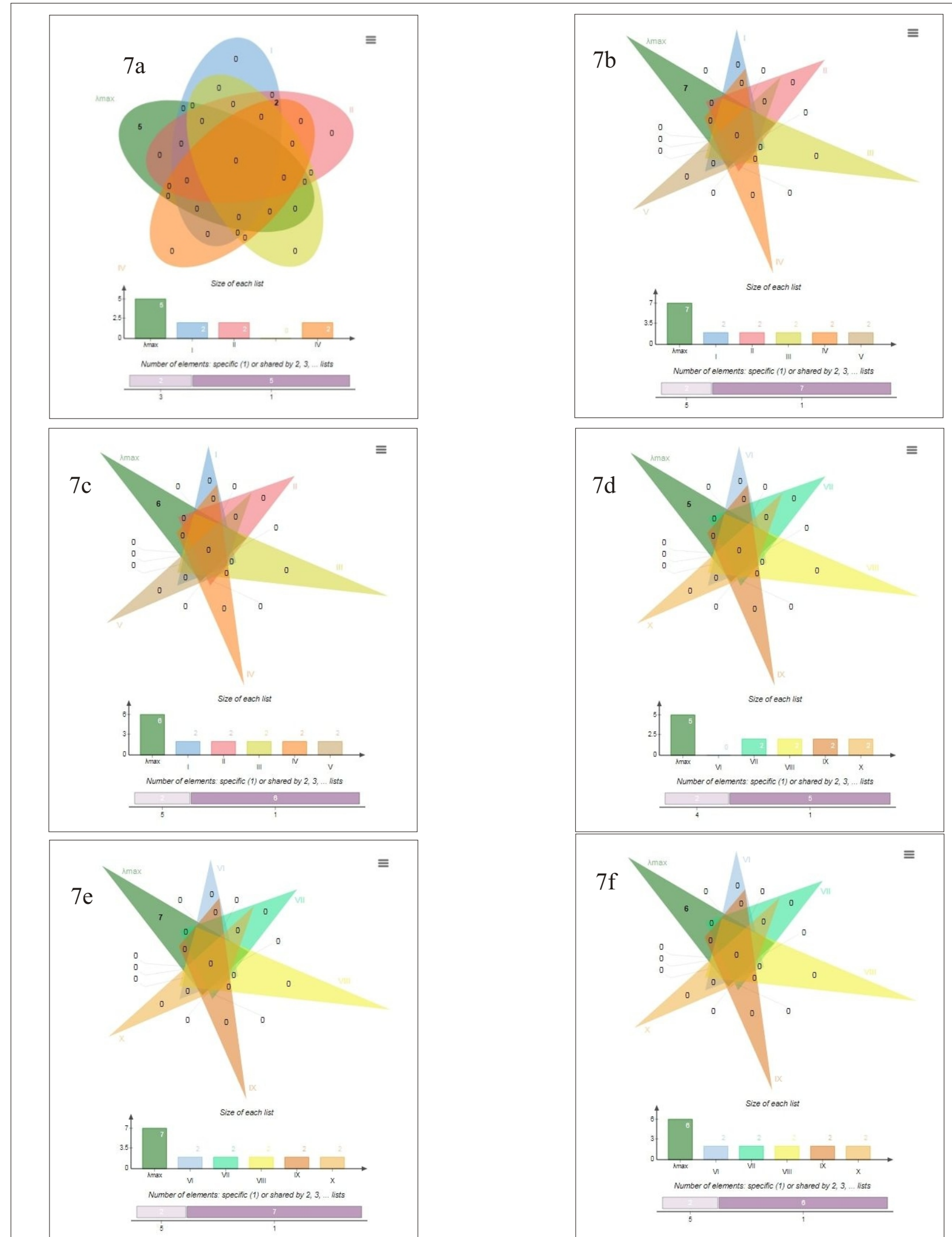

Fig.7 (a-c)- The shape corresponding to the lists involved in the intersection are highlighted in case of tissue, (a-455$463, \mathrm{~b}-510-540, c-632-644 \lambda \max )$. (d-f)- The shape corresponding to the lists involved in the intersection are highlighted in case of extracts, (a-455-463 $\lambda \max , \mathrm{b}-510-540, \mathrm{c}-632-644 \lambda \max )$. 
Table 3: Visible spectral characteristics of GNP swarms using T. heimii tissue sample and SWSE.

\begin{tabular}{|c|c|c|c|c|c|c|c|c|c|c|}
\hline \multirow{2}{*}{$\begin{array}{l}\text { Absorbance } \\
\text { Wavelength } \\
\text { (nm) }\end{array}$} & \multicolumn{5}{|c|}{ Tissue } & \multicolumn{5}{|c|}{ SWSE } \\
\hline & $\begin{array}{c}\text { I } \\
\text { Umbonal } \\
\text { tissue }\end{array}$ & $\begin{array}{c}\text { II } \\
\text { Pileus } \\
\text { context }\end{array}$ & $\begin{array}{c}\text { III } \\
\text { Lamellae }\end{array}$ & $\begin{array}{c}\text { IV } \\
\text { Stipe } \\
\text { Context }\end{array}$ & $\begin{array}{c}\mathrm{V} \\
\text { Pseudorrhiza } \\
\text { context }\end{array}$ & $\begin{array}{c}\text { VI } \\
\text { Umbonal } \\
\text { context }\end{array}$ & $\begin{array}{c}\text { VII } \\
\text { Pileus } \\
\text { context }\end{array}$ & $\begin{array}{c}\text { VIII } \\
\text { Lamellae }\end{array}$ & $\begin{array}{c}\text { IX } \\
\text { Stipe } \\
\text { context }\end{array}$ & $\begin{array}{c}\mathrm{X} \\
\text { Pseudorrhiza } \\
\text { context }\end{array}$ \\
\hline 455 & - & - & - & - & - & - & + & + & - & + \\
\hline 460 & - & - & - & + & - & - & - & - & + & - \\
\hline 461 & + & - & - & - & - & - & - & - & - & - \\
\hline 462 & + & + & - & - & - & - & - & - & - & - \\
\hline 463 & + & - & - & - & - & - & - & - & - & - \\
\hline 510 & - & - & - & - & - & - & - & - & - & + \\
\hline 511 & - & - & - & - & - & - & - & + & - & - \\
\hline 512 & - & - & - & - & - & - & + & - & - & - \\
\hline 519 & - & - & - & - & + & + & - & - & - & - \\
\hline 520 & + & - & + & + & - & - & - & - & - & - \\
\hline 522 & - & + & - & - & - & - & - & - & + & - \\
\hline 540 & - & - & - & - & + & - & - & - & - & - \\
\hline 632 & - & - & - & - & - & - & + & + & - & - \\
\hline 640 & - & - & - & - & - & + & - & - & - & - \\
\hline 641 & + & - & + & - & - & - & - & - & - & - \\
\hline 642 & - & + & - & - & + & - & - & - & - & + \\
\hline 643 & - & - & - & + & - & - & - & - & - & - \\
\hline 644 & - & - & - & - & - & - & - & - & + & - \\
\hline
\end{tabular}

2012). Absorbance reading is reported to be a direct indicator of the composition and size of NPs (Doak et al., 2010). SWSE prepared from same tissue do not produce GNPs of the same size or with same concentration. The GNP swarm population obtained is represented by 18 different size groups ranging from less than 5 to $100 \mathrm{~nm}$. The concentration of nanoparticles as function of optical absorbance ranges from 0.12 to 0.8 indicating that some bioreduction systems are much more efficient in the production of GNPs which includes GNPs of the size of less than 5 to $15 \mathrm{~nm}$.

It was found that stipe was showing most promising results in case of both tissue and SWSE. CIE chromaticity values ranged from $\mathrm{L}(16-75)$, a (3-33) and $\mathrm{b}$ (1-46) thus indicating the lightness from black to white, green to red and blue to yellow.Similar results were noticed in case of color difference amplification between GNPs in colorimetric analysis with actively controlled multiband illumination (Cheng et al., 2014).Choma values ranged from 4 to 47 and hue values from 40 to 199 indicating the strength or dominance of the hue, the quality of a color's purity, intensity or saturation (http://www.huevaluechroma.com/018.php).

GNPs produced using tissue showed low absorbance from min 0.10 to $\max 0.5 \mathrm{Lmol}^{-1} \mathrm{~cm}^{-1}$ whereas SWSE produced GNP with absorbance ranged from 0.1 to $0.8 \mathrm{~L} \mathrm{~mol}^{-1} \mathrm{~cm}^{-1}$ thereby indicating a more efficient system in cell free environment. Low absorbance at $0.19 \mathrm{~L} \mathrm{~mol}^{-1} \mathrm{~cm}^{-1}$ for intact tissue is indicative of the low concentration of GNP swarms. Mean absorbance at $0.40 \mathrm{~L} \mathrm{~mol}^{-1} \mathrm{~cm}^{-1}$ produced when tissue extract was used indicating almost double the bioreduction efficiency of intact tissue in case of GNP production. Thus, cell free environment is much better system to produce polydisperse GNP swarms in higher concentration.

In all 30 different peaks, ranging from 455 to $644 \mathrm{~nm}$, were obtained when tissue and its extract were used thus indicating the presence of nanoparticles of size ranging from 5 to $100 \mathrm{~nm}$ (https://www.sigmaaldrich.com). Mushrooms are rich in proteins and have high availability of the amino acids lysine, tryptophan, glutamic acid and aspartic acid (Hsu et al., 2002). It is also reported that certain mushroom extracts contain polysaccharide/oligosaccharide complex (Cho et al., 2003). FTIR studies have also shown the possible biomolecules responsible for capping and efficient stabilization of the metal nanoparticles synthesized using mushroom extract (Philip, 2009). It was noticed that certain SWSE and tissues produced specific wavelength when umbonal, pileus context, and pseudorrhizal context extract system was used resulting in the production of GNP swarms at wavelength of 455 , whereas umbonal tissue produced GNP swarms at $461 \lambda \max$ as well. Similar results were obtained in remaining reactions as shown in table 3. It was also noticed that there is a relationship between solubility and swarm formation and it could be a different molecule based bioreduction system. Jvenn's statistics charts give a simple and quick overview of the sizes of the different lists and of their overlaps. It permits to compare different Venn diagrams.

Table 4: Approximate GNP size range.

\begin{tabular}{|c|c|c|}
\hline $\begin{array}{c}\text { Wavelength reported in } \\
\text { present assay (nm) }\end{array}$ & $\begin{array}{c}\text { Approximate GNP size } \\
\text { range (nm) }\end{array}$ & Reference \\
\hline $455,460,461,462,463$ & $<5$ & Ted Pella Inc. \\
\hline 510,511 & 5 & Ted Pella Inc. \\
\hline 512,519 & 10 & Sigma-Aldrich \\
\hline 520,522 & 15 & Sigma-Aldrich, Ted Pella Inc. \\
\hline 540 & $10-30$ & Radtsiget al., 2016 \\
\hline 632 & $50-80$ & Sigma-Aldrich \\
\hline 640 & $80-100$ & Sigma-Aldrich \\
\hline 641 & 100 & Sigma-Aldrich, Ted Pella Inc. \\
\hline $642,643,644$ & 100 &
\end{tabular}


Preliminary characterization of GNP swarms, as has been attempted during the present investigations while working with T. heimii, is quite important. In comparison, high throughput screening systems are wasteful and time consuming but preliminary characterization can also help in standardization of the procedure and also there is no waste of resources.

\section{CONCLUSIONS}

The present work demonstrates that simple and easy to use mobile digital Colorimeter Apps can be used for primary optical characterization of swarms of Gold nanoparticles. This is quite useful in rapid screening of large number of microbiological gold bioreduction systems. The spectral absorbance profile detected in visible range also helps in understanding the presumptive size of GNPs in swarms. For high throughput screening systems the development of more such mobile based apps is recommended. The present approach has helped us in the fabrication of a very sensitive Gold biosensor.

\section{ACKNOWLEDGEMENTS}

The authors would like to thank RNSB project for the support. This work was also supported by UGC SAP Phase III Biodiversity, Bioprospecting program and Goa University Fungus Culture Collection GUFCC). First author also acknowledges UGC, NF OBC Junior Research fellowship. Thanks are due to Dr. Absar Ahmad, Director, Interdisciplinary Center for Nanotechnology AMU for guidance.

\section{REFERENCES}

Bardou, P., Mariette, J., Escudié, F., Djemiel, C. and Klopp, C. 2014. jvenn: an interactive Venn diagram viewer. BMC bioinformatics 15 (1): 1-7. Https://doi.org/ 10.1186/1471-2105-15-293.

Cheng, X., Dai, D., Yuan, Z., Peng, L., He, Y. and Yeung, E.S. 2014. Color difference amplification between gold nanoparticles in colorimetric analysis with actively controlled multiband illumination. Analytical Chemistry 86 (15): 7584-7592.

Cho, J., Kang, J.S., Long, P.H., Jing, J., Back, Y. and Chung, K.S.2003. Antioxidant and memory enhancing effects of purple sweet potato anthocyanin and Cordyceps mushroom extract. Archives of Pharmacal Research 26 (10): 821-825.

De Souza, R.A. and Kamat, N.M. 2018a. Evaluation and characterization of pellet morphology of genus Termitomyces heimii of a wild tropical edible mushroom. Journal of Pharmaceutical Chemical and Biological Sciences 6(4): 320-328.

De Souza, R.A. and Kamat, N.M. 2019. Termitomyces holomorph benefits from anomalous Sulphur content in teleomorph. International Journal of Life Sciences Research 1: 186-192.

De Souza, R.A., Kamat, N.M. and Nadkarni, V.S. 2018 b. Purification and characterisation of a Sulphur rich melanin from edible mushroom Termitomyces albuminosus Heim. Mycology 9 (4): 296-306.

Doak, J., Gupta, R.K., Manivannan, K., Ghosh, K. and Kahol, P.K. 2010. Effect of particle size distributions on absorbance spectra of gold nanoparticles. Physica E: Low-dimensional Systems and Nanostructures $\mathbf{4 2}$ (5): 1605-1609.

D'Souza, R.A. and Kamat, N.M. 2017. Potential of FTIR spectroscopy in chemical characterization of Termitomyces pellets. Journal of Applied Biology \& Biotechnology 5(04): 080-084.

Haiss, W., Thanh, N.T., Aveyard, J. and Fernig, D.G. 2007. Determination of size and concentration of gold nanoparticles from UV-Vis spectra. Analytical Chemistry 79 (11): 4215-4221.

Heim, Roger.1942. New Descriptive Studies on Termitophilic Agarics from Tropical Africa. Arch. Mus. Natl. Hist. Nat. Paris. 6: 1-133.

Heim, R. 1977. Termites and fungi; termitophilic fungi from black Africa and southern Asia, Societe Nouvelle des Eds. Boubee. Paris. ISBN 2850040045.1-207

Hsu, T.H., Shiao, L.H., Hsieh, C. and Chang, D.M. 2002. A comparison of the chemical composition and bioactive ingredients of the Chinese medicinal mushroom DongChongXiaCao, its counterfeit and mimic, and fermented mycelium of Cordyceps sinensis. Food chemistry 78(4): 463-469.

http://bioinfo.genotoul.fr/jvenn/example.html (last accessed on $13 / 09 / 2019$ )

http://bioinformatics.psb.ugent.be/ (last accessed on 16/01/2020)

http://www.huevaluechroma.com/015.php (last accessed on 02/05/2020)

http://researchlabtools.blogspot.com (last accessed on 03/06/2020)

https://www.sigmaaldrich.com (last accessed on 05/04/2020)

https://www.tedpella.com (last accessed on 05/04/2020)

Jana, N. R., Gearheart, L. and Murphy, C. J. 2001. Seeding growth for size control of 5-40 nm diameter gold nanoparticles. Langmuir. 17(22): 6782-6786.

Kagan, D., Balasubramanian, S., and Wang, J. 2011. Chemically triggered swarming of gold microparticles. Angewandte Chemie (International Edition) 50 (2): 503-506.

Kalia, A. and Kaur, G., 2018. Biosynthesis of Nanoparticles Using Mushrooms. In: Biology of Macrofungi, pp. 351-360. Springer, Cham.

Meruga, Jeevan Manikyarao, Aravind Baride, William Cross, Jon J. Kellar, and P. Stanley May. 2014. Red-greenblue printing using luminescence-upconversion inks. Journal of Materials Chemistry12:2221-2227. 
Natarajan, K. 1979. South Indian Agaricales V: Termitomyces heimii. Mycologia 71(4): 853-855.

Philip, D. 2009. Biosynthesis of $\mathrm{Au}, \mathrm{Ag}$ and $\mathrm{Au}-\mathrm{Ag}$ nanoparticles using edible mushroom extract. Spectrochimica Acta Part A: Molecular and Biomolecular Spectroscopy 73 (2): 374-381.

Ravindranath, R., Periasamy, A. P., Roy, P., Chen, Y. W., and Chang, H. T.2018. Smart app-based on-field colorimetric quantification of mercury via analyteinduced enhancement of the photocatalytic activity of $\mathrm{TiO} 2-\mathrm{Au}$ nanospheres. Analytical and bioanalytical chemistry 410 (18): 4555-4564.

Sen, I.K., Maity, K. and Islam, S.S. 2013. Green synthesis of gold nanoparticles using a glucan of an edible mushroom and study of catalytic activity. Carbohydrate polymers 91(2): 518-528.

Solomon, C. and Breckon, T., 2011. Fundamentals of Digital Image Processing: A practical approach with examples in Matlab. John Wiley \& Sons. 